\title{
Perception and Stigma Regarding Eye Donation among Employees in a Tertiary Care Centre
}

\author{
Anuja Desai* ${ }^{(0)}$, Parin Mehta \\ Department of Ophthalmology, Kusum Dhirajlal Hospital, Ahmedabad, Gujarat, India \\ Email: ^anujakdesai@gmail.com
}

How to cite this paper: Desai, A. and Mehta, P. (2021) Perception and Stigma Regarding Eye Donation among Employees in a Tertiary Care Centre. Open Journal of Ophthalmology, 11, 332-338. https://doi.org/10.4236/ojoph.2021.114027

Received: November 4, 2021

Accepted: November 26, 2021

Published: November 29, 2021

Copyright $\odot 2021$ by author(s) and Scientific Research Publishing Inc. This work is licensed under the Creative Commons Attribution International License (CC BY 4.0).

http://creativecommons.org/licenses/by/4.0/

\section{(c) (i) Open Access}

\begin{abstract}
Purpose: To understand the awareness and knowledge about eye donation in the employees of a tertiary hospital. Methods: A structured Google form based cross-sectional survey was conducted among 678 employees comprising of medical, nursing, students and paramedical staff. The responses were evaluated in an Excel spreadsheet and tabulated. Results: 86\% of the employees had awareness about eye donation, however, their knowledge regarding the same was either inadequate or incorrect. Only $63 \%$ had pledged their eyes and of the remaining, about $63.5 \%$ were willing to pledge. Conclusion: Awareness levels are high among the hospital workers but the lack of basic information is alarming. These need to be improved so that common people can be motivated to pledge and donate their eyes and correct the disparity between the need and availability of donor eyes for transplants.
\end{abstract}

\section{Keywords}

Awareness, Corneal Blindness, Eye Donation, Keratoplasty, Willingness to Pledge

\section{Introduction}

Blindness and visual impairment are the terms used to define a decrease in vision from various diseases. The definition of blindness adopted by the National Programme for Control of Blindness and Visual Impairment in the Ministry of Health and Family Welfare is visual acuity $<3 / 60$ in the better eye with available correction or visual acuity of $<3 / 60$ in the better eye [1].

There are 8 million blind and 62 million visually impaired people in India, which amounts to roughly one-fourth of the global burden [2]. Of these, corneal blindness remains to be the third leading cause of avoidable blindness. This encompasses both preventable and treatable corneal diseases. Approximately 68 
lakh people have corneal blindness in at least one eye; of this number, 10 lakh people are blind in both their eyes [3]. The National Blindness and Visual Impairment Survey 2019 reported that corneal blindness was the leading cause of blindness among patients aged less than 50 years in India, accounting for 37.5\% of the cases and was the second leading cause of blindness in patients above the age of 50 years [4]. Every year around 25,000 - 30,000 people with corneal blindness are added to this number bringing the prevalence to $0.16 \%$. The major causes of corneal blindness noted are post-surgical bullous keratopathy, corneal dystrophy and degeneration and trachoma. Infectious keratitis during childhood and adulthood, trauma and vitamin A deficiency also play an essential role. The final treatment option for such causes of blindness is a corneal transplant or keratoplasty. This depends on a matching supply-demand cycle which is unfortunately not the scenario in India. We need approximately 2.7 lakh corneas; however, we get around 63,000 every year [5]. This gross disparity between the need and availability is what we must strive to overcome.

Healthcare personnel must have adequate information about the same as they are the first point of communication with the kin of the deceased. The shortage of eye donations needs to be addressed at all levels of healthcare, and hence all workers should be given proper education. We conducted this survey to assess the information hospital employees have despite working in the medical field. We hope to improve their knowledge so that it can have some contribution to improving the dismal scenario in eye donations.

\section{Materials and Methods}

A community-based cross-sectional study was conducted amongst employees working in a tertiary care centre in western India between 27 August 2021 to 29 August 2021. A standard pre-designed, close-ended, structured questionnaire was created using Google forms and circulated through social media \& email to all the employees, including doctors. The in house transplant coordinator was explained the content and purpose of the study as he was the single point of communication amongst the participants. The questions ranged from basic demographics, awareness and knowledge about eye donation, and ultimately willingness to pledge their eyes. The participants included doctors, nurses, paramedical staff, students, and managers working within the hospital premises. The results were extrapolated from the Google forms into a Microsoft Excel spreadsheet and analysed.

\section{Results}

The primary aim of our study was to assess the level of information that the employees had regarding eye donation. We conducted the survey among $678 \mathrm{em}-$ ployees of the hospital, of which 178 (26.25\%) were nurses or nursing tutors, 126 (18.58\%) were nursing college students, $99(14.60 \%)$ were paramedical technicians, $76(11.21 \%)$ were executives, 65 (9.59\%) were senior consultants, 50 
(7.37\%) were interns or trainees, $47(6.93 \%)$ were managers, and $37(5.46 \%)$ were medical officers. Detailed age-wise distribution is shown in Table 1 . These included 380 (56\%) females and 298 (44\%) males with a mean age of $35.5 \pm 1.2$ years and $42.1 \pm 1.1$ years, respectively.

The questions in the survey were divided into demographic data, eye donation awareness and willingness to pledge. Table 2 shows the responses to the questions about eye donation. We found that 580 responders that account for $86 \%$ of the employees, were aware that eye donation is possible. However, there were a lot of people who had inadequate information about other questions. Notably, $50 \%$ (340) believed that the entire eye could be transplanted. Also, 25\% (167) of respondents had misconceptions pertaining to vision after death.

Incorrect answers to four essential questions which grasped our attention are mentioned in Figure 1.

These questions constitute the most common myths that people have about donating eyes. When asked if a living person can donate eyes, 30\% (104) of nurses, nursing tutors and $17 \%$ (58) of nursing college students responded yes. $25 \%$ (54) of nurses and 16\% (36) of executives said that buying/selling of eyes is legal. $31 \%$ (84) of nurses and 15\% (41) of nursing students believed eye donation causes facial disfigurement and scarring. While $25 \%$ (86) of the nurses and $16 \%$ (56) of paramedical technicians thought that the entire eye could be transplanted.

\section{Discussion}

Corneal blindness includes a large proportion of avoidable blindness in India. This also depends on the prevalence of endemic corneal diseases in the country and the community awareness of eye donation. Community awareness begins at the level of healthcare personnel who are the first responders in times of organ donation. If they are adequately informed about eye donation, only then they

Table 1. Age-wise distribution of participants across the organization.

\begin{tabular}{|c|c|c|c|c|c|c|c|}
\hline \multirow{2}{*}{ DESIGNATION } & \multicolumn{6}{|c|}{ AGE } & \multirow{2}{*}{ Grand Total } \\
\hline & $18-24$ & $25-34$ & $35-44$ & $45-54$ & $55-64$ & $65+$ & \\
\hline Executive & 16 & 33 & 21 & 4 & 1 & 1 & $76(11.21 \%)$ \\
\hline Interns/Trainee & 33 & 9 & 4 & 3 & 1 & 0 & $50(7.37 \%)$ \\
\hline Manager & 1 & 19 & 17 & 10 & 0 & 0 & $47(6.93 \%)$ \\
\hline Medical Officer & 4 & 20 & 8 & 4 & 1 & 0 & $37(5.46 \%)$ \\
\hline Nurse/Nurse Tutor & 79 & 82 & 15 & 1 & 1 & 0 & $178(26.25 \%)$ \\
\hline Nursing College Student & 110 & 14 & 0 & 1 & 1 & 0 & $126(18.58)$ \\
\hline Paramedical technician & 18 & 52 & 23 & 4 & 2 & 0 & $99(14.60 \%)$ \\
\hline Senior Consultant & 1 & 18 & 26 & 12 & 7 & 1 & $65(9.59 \%)$ \\
\hline Grand Total & $262(38.64 \%)$ & $247(36.43 \%)$ & $114(16.81 \%)$ & $39(5.75 \%)$ & $14(2.06 \%)$ & $2(0.29 \%)$ & 678 \\
\hline
\end{tabular}


Table 2. Survey responses from the participants.

\begin{tabular}{|c|c|c|}
\hline Sr. No. & Questions & Responses $(n=678)$ \\
\hline \multirow[t]{3}{*}{1} & Can eyes be donated? & \\
\hline & No & $98(14 \%)$ \\
\hline & Yes & $580(86 \%)$ \\
\hline \multirow[t]{3}{*}{2} & Is there an age limit for eye donation? & \\
\hline & No & $462(68 \%)$ \\
\hline & Yes & $216(32 \%)$ \\
\hline \multirow[t]{3}{*}{3} & Can a living person donate his/her eyes? & \\
\hline & No & $328(48 \%)$ \\
\hline & Yes & $350(52 \%)$ \\
\hline \multirow[t]{4}{*}{4} & Within how many hours of death can eyes be removed? & \\
\hline & $<8$ hours & $523(77 \%)$ \\
\hline & $>12$ hours & $29(4 \%)$ \\
\hline & $8-12$ hours & $126(19 \%)$ \\
\hline \multirow[t]{3}{*}{5} & Can my blood relatives give consent for donation after my death? & \\
\hline & No & $97(14 \%)$ \\
\hline & Yes & $581(86 \%)$ \\
\hline \multirow[t]{3}{*}{6} & Is buying/selling of eyes legal? & \\
\hline & No & $459(68 \%)$ \\
\hline & Yes & $219(32 \%)$ \\
\hline \multirow[t]{3}{*}{7} & Does the removal of eye cause facial disfigurement? & \\
\hline & No & $408(60 \%)$ \\
\hline & Yes & $270(40 \%)$ \\
\hline \multirow[t]{3}{*}{8} & If I donate my eyes when I die, I will be blind by birth in my next life. & \\
\hline & FALSE & $511(75 \%)$ \\
\hline & TRUE & $167(25 \%)$ \\
\hline \multirow[t]{3}{*}{9} & Can the entire eye be transplanted? & \\
\hline & No & $340(50 \%)$ \\
\hline & Yes & $338(50 \%)$ \\
\hline \multirow[t]{3}{*}{10} & If I have cataract or have been operated for cataract, my eyes cannot be donated. & \\
\hline & FALSE & $366(54 \%)$ \\
\hline & TRUE & $312(46 \%)$ \\
\hline \multirow[t]{3}{*}{11} & Living human beings can pledge their eyes. Have you pledged your eyes? & \\
\hline & No & $250(37 \%)$ \\
\hline & Yes & $428(63 \%)$ \\
\hline
\end{tabular}




\section{Designation wise incorrect answers}

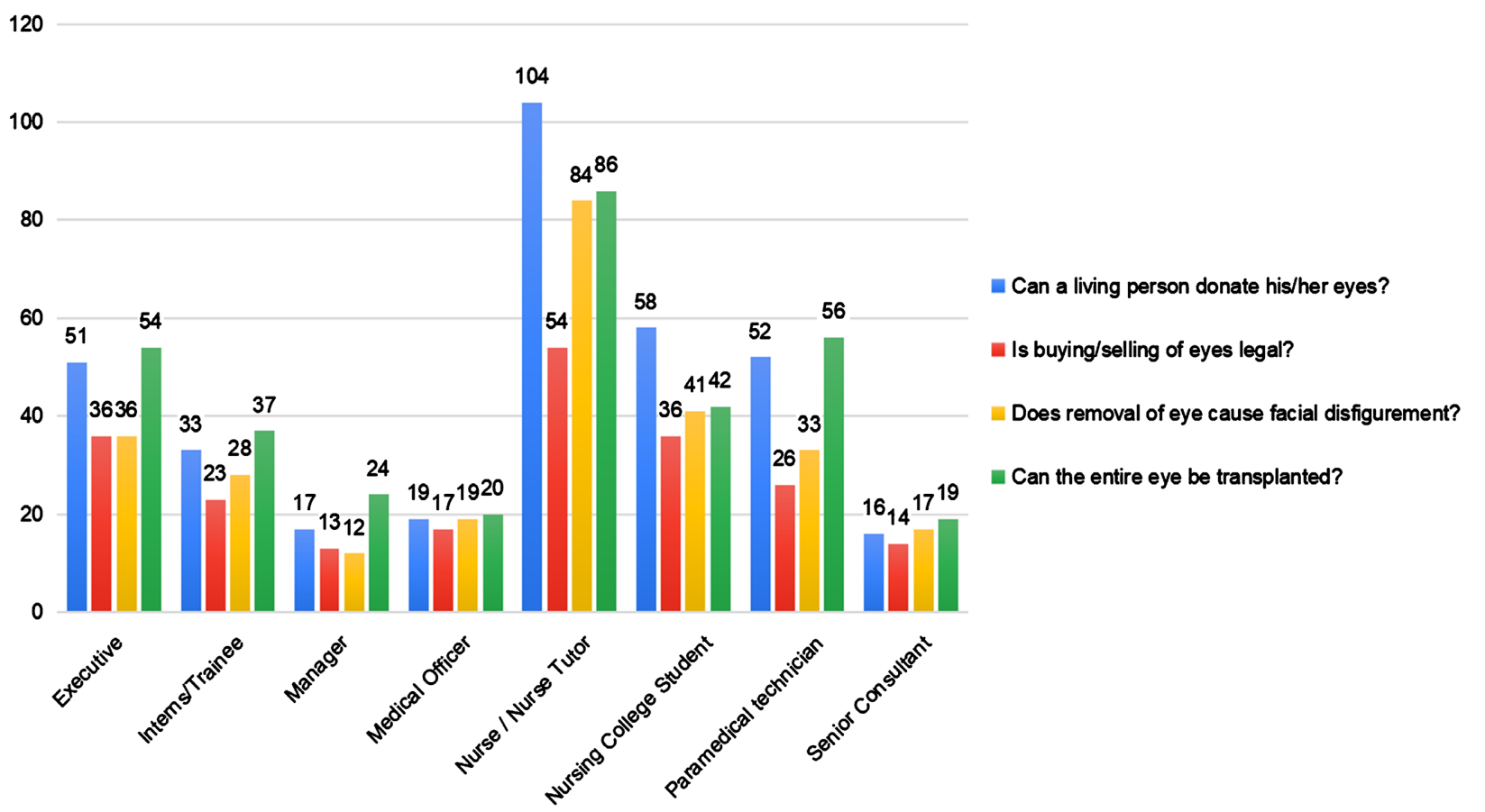

Figure 1. Incorrect responses to eye donation knowledge-based questions with respect to different participant groups.

can educate locals, and that will, in turn, lead to more pledges for eye donation and encourage blood relatives to honour that pledge at the time of death.

This study aimed to address the significant disparity between the perception and awareness about eye donation among different healthcare workers. Doctors and particularly ophthalmologists have detailed knowledge about eye donation. Still, the data from our study shows a lack of the same in other groups despite working in a hospital with eye retrieval facilities and programs. These differences can be attributed to differences in the level of information grasped by non-medico subjects. A study from a hospital set up in India revealed that $59.4 \%$ of their staff had significant misconceptions about different organ transplants, including the eye [6]. This study reinforces the same issue about rampant myths not only about eye donation but also other organs.

$63 \%$ of our participants have already pledged their eyes. Of the remaining $37 \%$ participants, $67.5 \%$ were willing to pledge their eyes, demonstrating that awareness needs to be initiated at their level to proportionately include their families, which can create a mass chain of communication. In other population-based surveys from India, 41.5\% from Delhi, 52\% from north-western India and 44.9\% from Hyderabad were willing to donate [7] [8].

Our study reported $86 \%$ of subjects being aware regarding eye donation. In a survey among the south Indian population, around $50.7 \%$ of the subjects had awareness about eye donation [9]. A sizeable urban population-based survey showed that only $30.7 \%$ had information about eye donation, and only $0.1 \%$ had 
pledged [10]. Similarly, a large study from rural Andhra Pradesh (32.9\%) showed very little population awareness regarding eye donation [11]. This indicates the imbalance in awareness of eye donation and the inadequate spread of knowledge between rural and urban areas.

There are many misconceptions about different aspects of eye donation that need to be addressed at grassroots levels. Myths about eye donation coupled with lack of knowledge are a massive barrier to organ donation and can be considered a hurdle in convincing the people and obtaining enough pledges. Mass media needs to be utilized more if we increase the number of donor corneas each year. For multi-speciality hospitals with eye departments, whether governmental or not, their employees of all levels must actively spread accurate information among the patients and their kin [12]. This will proactively increase the rates of donation across the country in rural as well as urban areas. Apart from the who, what, when and how of eye donation, people need to understand the importance of discussion with family members, should the need arise. They will be the linchpin to motivate from within the family and surrounding community.

Many countries have the concept of "presumed consent", where the dead person is assumed to be a donor even if they have not registered themselves when alive. After appropriate consent from the next-of-kin, eye donation is carried out. This concept in India is not yet materialized, and there have been no known efforts to do so. India has the "opt-in" system where the donor has to register themselves, and then only eye donation can be made with prior consent from the donor or legal next of kin. If we are to balance the awareness to action ratio for corneas, we need some specific changes in the legislation [13].

\section{Conclusion}

This survey attests to the fact that awareness regarding eye donation is lacking in some proportion among the employees of a tertiary care hospital. The underutilization of the hospital workforce can be a hindrance in spreading awareness. It is important to guide them with proper information so that they can be a source of information to the general population.

\section{Conflicts of Interest}

The authors declare no conflicts of interest regarding the publication of this paper.

\section{References}

[1] Malhotra, S., Prasad, M., Vashist, P., Kalaivani, M. and Gupta, S.K. (2019) Prevalence of Blindness in India: A Systematic Review and Meta-Analysis. The National Medical Journal of India, 32, 325. https://doi.org/10.4103/0970-258X.303612

[2] Vashist, P., Senjam, S.S., Gupta, V., Gupta, N. and Kumar, A. (2017) Definition of Blindness under National Programme for Control of Blindness: Do We Need to Revise It? Indian Journal of Ophthalmology, 65, 92-96.

https://doi.org/10.4103/ijo.IJO $869 \quad 16$

[3] https://www.nhp.gov.in/national-eye-donation-fortnight-2021_pg 
[4] Dr. Rajendra Prasad Centre for Ophthalmic Sciences, AIIMS (2020) National Blindness and Visual Impairment Survey India 2015-2019: A Summary Report. New Delhi.

[5] Chowdhury, R.K., Dora, J. and Das, P. (2021) Awareness of Eye Donation among Medical and Nursing Students: A Comparative Study. Indian Journal of Ophthalmology, 69, 1511-1515. https://doi.org/10.4103/ijo.IJO 205320

[6] Singh, P., Kumar, A., Pandey, C.M. and Chandra, H. (2002) Level of Awareness about Transplantation, Brain Death and Cadaveric Organ Donation in Hospital Staff in India. Progress in Transplantation, 12, 289-292. https://doi.org/10.1177/152692480201200409

[7] Duggal, M., Brar, G.S., Prasad, V.S. and Gupta, A. (2003) Public Attitudes toward Eye Donation in Northwestern India. Transplantation Proceedings, 35, 19-20. https://doi.org/10.1016/S0041-1345(02)03826-5

[8] Dandona, R., Dandona, L., Naduvilath, T.J., McCarty, C.A. and Rao, G.N. (1999) Awareness of Eye Donation in an Urban Population in India. Australian and New Zealand Journal of Ophthalmology, 27, 166-169. https://doi.org/10.1046/j.1440-1606.1999.00196.x

[9] Priyadarshini, B., Srinivasan, M., Padmavathi, A., Selvam, S., Saradha, R. and Nirmalan, P.K. (2003) Awareness of Eye Donation in an Adult Population of Southern India: A Pilot Study. Indian Journal of Ophthalmology, 51, 101-104.

[10] Suresh, K., Priyanka, P. and Shanmugha, P. (2008) Awareness of Eye Donation in Rural and Hospital-Based Population. Indmedica, 4, 6-9.

[11] Krishnaiah, S., Kovai, V., Nutheti, R., Shamanna, B.R., Thomas, R. and Rao, G.N. (2004) Awareness of Eye Donation in the Rural Population of India. Indian Journal of Ophthalmology, 52, 73-78.

[12] Dhaliwal, U. (2002) Enhancing Eye Donation Rates. Training Students to Be Motivators. Indian Journal of Ophthalmology, 50, 209-212.

[13] Saini, J.S., Reddy, M.K., Jain, A.K., Ravindra, M.S., Jhaveria, S. and Raghuram, L. (1996) Perspectives in Eye Banking. Indian Journal of Ophthalmology, 44, 47. 